\title{
HUBUNGAN GAYA BELAJAR DENGAN PRESTASI BELAJAR MATEMATIKA SISWA KELAS XI SMK MUHAMMADIYAH 1 PALEMBANG
}

\author{
Septi Eka Wahyuni ${ }^{1}$, Muslimin Tendri ${ }^{2}$, Nyimas Inda Kusumawati ${ }^{3}$ \\ Universitas Muhammadiyah Palembang ${ }^{1,2,3}$ \\ septiekawahyuni07@gmail.com ${ }^{1}$
}

\begin{abstract}
ABSTRAK
Gaya belajar terdiri dari: gaya belajar Visual, gaya belajar Auditory, dan gaya belajar Kinestetik. Ketiga gaya belajar ini mempengaruhi prestasi belajar siswa. Prestasi belajar diartikan sebagai hasil yang diperoleh karena adanya aktivitas belajar yang telah dilakukan. Penelitian ini bertujuan untuk mengetahui apakah ada hubungan gaya belajar dengan prestasi belajar matematika siswa kelas XI SMK Muhammadiyah 1 Palembang. Penelitian dilaksanakan pada bulan Oktober 2020. Jenis penelitian ini menggunakan metode penelitian kuantitatif. Data dikumpulkan menggunakan instrumen angket yang dimuat pada google form sebagai variabel bebas. Sedangkan variabel terikatnya nilai raport siswa. Data penelitian ini dianalisis dengan menggunakan rumus korelasi product moment dan rumus regresi sederhana dibantu program SPSS. Hasil penelitian ini menunjukkan bahwa ada hubungan gaya belajar dengan prestasi belajar matematika siswa kelas XI di SMK Muhammadiyah 1 Palembang.
\end{abstract}

Kata kunci : gaya belajar, prestasi belajar matematika

\begin{abstract}
Visual learning styles, auditory learning styles, and kinesthetic learning styles are the three types of learning styles. These three learning styles have an impact on student achievement. Learning achievement is defined as the outcomes of learning activities that have been completed. The purpose of this study is to see if there is a connection between learning styles and mathematics learning achievement of class XI students at SMK Muhammadiyah 1 Palembang. The study was carried out in October 2020. Quantitative research methods are used in this type of study. Data were collected using a questionnaire instrument that was loaded as an independent variable on a Google form. The value of student report cards is the dependent variable. The data of this study were analyzed using the product moment correlation formula and a simple regression formula assisted by the SPSS program. The findings of this study suggest that there is a connection between learning styles and mathematics learning achievement in class XI students at SMK Muhammadiyah 1 Palembang.
\end{abstract}

Keywords : learning styles, mathematics learning achievement 


\section{PENDAHULUAN}

Belajar memiliki pengertian memperoleh pengetahuan atau menguasai pengetahuan. Pengetahuan yang diperoleh dapat melalui pengalaman, mengingat, menguasai pengalaman, mendapatkan informasi atau menemukan informasi. Dengan demikian, belajar matematika memiliki arti dasar adanya aktivitas atau kegiatan penguasaan tentang ilmu matematika.

Menurut Peraturan Menteri Pendidikan Nasional Republik Indonesia nomor 22 tahun 2006 diungkapkan juga bahwa mata pelajaran matematika perlu diberikan kepada semua peserta didik mulai dari sekolah dasar untuk membekali peserta didik dengan kemampuan berpikir logis, analitis, sistematis, kritis, dan kreatif, serta kemampuan bekerja sama.

Setiap peserta didik memiliki tingkat kecerdasan yang berbeda-beda, karakter belajar yang berbeda, kebiasaan yang berbeda saat belajar dan cara belajar yang berbeda. Begitupun juga kemampuan peserta didik untuk memahami dan menyerap pelajaran juga berbeda, ada peserta didik yang langsung bisa tanggap ketika guru menjelaskan, ada peserta didik yang harus melihat gambar atau membaca buku terlebih dahulu agar bisa memahami pelajaran tersebut, tetapi ada juga peserta didik yang lebih suka membuat kelompok untuk mendiskusikan pertanyaan yang berhubungan dengan pelajaran tersebut. Berhasil atau gagalnya pencapaian tujuan pendidikan tersebut bergantung pada gaya belajar peserta didik.

Gaya Belajar terbagi menjadi gaya belajar visual (visual learner), gaya belajar autitif (auditory lerner), gaya belajar kinestetik (tactual learner). Gaya belajar tersebut memiliki penekanan-penekanan masing-masing, meskipun perpaduan dari ketiganya sangatlah baik, tetapi pada saat siswa akan menggunakan salah satu dari ketiga gaya belajar tersebut maka prestasi belajar peserta didik akan ada peningkatan.

Berikut tipe gaya belajar menurut DePorter dan Hernacki (2014): (a) Gaya Belajar Visual; individu memiliki kecenderungan gaya belajar visual lebih senang dengan melihat apa yang sedang dipelajari. Gambar atau simbol akan membantu mereka yang memiliki gaya belajar visual untuk lebih memahami ide informasi yang disajikan dalam bentuk penjelasan. Apabila seseorang menjelaskan sesuatu kepada orang yang memiliki kecenderungan gaya belajar visual, mereka akan menciptakan gambaran mental tentang apa yang dijelaskan oleh orang tersebut. (b) Gaya Belajar Auditorial; individu memiliki kecenderungan gaya belajar auditorial kemungkinan akan belajar lebih baik dengan cara mendengarkan. Mereka menikmati saat-saat mendengarkan apa yang disampaikan oleh orang lain. Karakteristik model belajar seperti ini benar-benar menempatkan pendengaran sebagai alat utama menyerap informasi atau pengetahuan. (c) Gaya Belajar Kinestetik; individu yang memiliki kecenderungan gaya belajar kinestetik akan lebih baik apabila terlihat secara fisik dalam kegiatan langsung. Mereka akan belajar apabila mereka mendapat kesempatan untuk memanipulasi media untuk mempelajari informasi baru.

Menurut hasil penelitian yang dilakukan oleh Pujiarti (2013) mengenai hubungan antara gaya belajar dengan prestasi belajar siswa kelas V SD Negeri percobaan 4 Wates Kulon Progo tahun ajaran 2012/2013, ditarik kesimpulan bahwa ada hubungan positif dan signifikan antara gaya belajar dengan prestasi belajar siswa. Begitu juga penelitian Tualeka (2020) menunjukkan hasil bahwa ada pengaruh gaya belajar siswa terhadap hasil belajar matematika kelas VIII SMP Negeri 23 Ambon. 
Namun ada juga penelitian dari Wardhani, Hanik, dan Wulandari (2016) yang menunjukkan bahwa tidak ada pengaruh yang signifikan antara gaya belajar mahasiswa terhadap hasil belajar matematika mahasiswa Teknologi Industri Pertanian Universitas Trunojoyo. Hal ini berarti gaya belajar tidak dapat memprediksi hasil belajar matematika pada mahasiswa Teknologi Industri Pertanian di masa yang akan datang. Begitu juga hasil penelitian Budiarti dan Jabar (2016) menunjukkan bahwa tidak terdapat pengaruh signifikan gaya belajar terhadap hasil belajar matematika siswa kelas VIII SMPN 2 Banjarmasin tahun ajaran 2015/2016.

Dengan demikian perlu dilihat lagi bagaimana peran gaya belajar ini dalam meningkatkan hasil belajar atau prestasi siswa. Karena menurut teori, bila seorang anak diajar sesuai dengan gaya belajarnya masing-masing maka akan memperoleh hasil yang maksimal. Gaya belajar ini akan menciptakan sebuah pembelajaran terpadu yang akan mendorong keterlibatan peserta didik dalam belajar, membuat anak terlibat secara aktif dalam proses pembelajaran. Hal ini menunjukkan bahwa gaya belajar setiap peserta didik memainkan peran penting dalam pembelajaran.

Menyadari bahwa gaya belajar peserta didik adalah hal yang sangat penting bagi guru dan peserta didik untuk menghasilkan proses pembelajaran yang sukses, maka dilakukan penelitian untuk mengetahui apakah ada hubungan gaya belajar dengan prestasi belajar matematika siswa kelas XI di SMK Muhammadiyah 1 Palembang.

Terpilihnya siswa kelas XI di SMK Muhammadiyah 1 Palembang karena prestasi belajar siswa termasuk kategori sedang ke bawah khususnya pada mata pelajaran matematika. Perlu dilihat lagi kondisi siswanya, agar dapat dipetakan gaya belajarnya, dan dapat diupayakan pembelajaran yang lebih baik sesuai dengan gaya belajarnya.

\section{METODE}

Jenis penelitian yang digunakan adalah penelitian kuantitatif korelasi. Penelitian korelasi adalah penelitian yang dilakukan untuk mengetahui tingkat hubungan antara dua variabel atau lebih, tanpa melakukan perubahan, tambahan atau manipulasi terhadap data yang sudah ada. Dalam penelitian kuantitatif/positivistik, yang dilandasi pada suatu asumsi bahwa suatu gejala itu dapat diklasifikasi, dan hubungan gejala bersifat kausal (sebab-akibat), maka peneliti dapat melakukan penelitian dengan memfokuskan kepada beberapa variabel saja (Sugiyono, 2011).

Populasi penelitian ini adalah seluruh kelas XI SMK Muhammadiyah 1 Palembang. Sampel dalam penelitian ini diambil $15 \%$ dari populasi, yaitu $15 \% \times 7$ kelas $=1$ kelas. Penelitian dilaksanakan pada bulan Oktober 2020 .

Teknik pengambilan sampel yang digunakan dalam penelitian ini adalah cluster random sampling yang berarti teknik pengambilan sampel yang memberi peluang sama kepada seluruh anggota populasi untuk dapat dipilih sebagai anggota sampel. Pengambilan sampel dari anggota populasi ini dilakukan secara acak dari beberapa kelas dengan cara diundi. Kelas yang terpilih menjadi sampel adalah kelas XITKJ.1 yang berjumlah 35 siswa.

Teknik pengumpulan data yang digunakan terdiri dari angket dan data primer yang diperoleh dari guru. Angket yang diberikan berupa angket tertutup. Penyebaran angket dilakukan secara online dengan menggunakan google form melalui link akses berikut https://forms.gle/ymLm5CHh2tQUN7oX8 dan skala yang digunakan untuk 
jawaban dari setiap pernyataan adalah skala likert. Data prestasi belajar matematika siswa diperoleh dari guru mata pelajaran di SMK Muhammadiyah 1 Palembang.

Analisis data dalam penelitian ini diperoleh dengan menggunakan analisis statistik untuk mengetahui persentase tingkat gaya belajar matematika dengan prestasi belajar matematika siswa kelas XI SMK Muhammadiyah 1 Palembang. Data gaya belajar siswa dihitung dengan rumus berikut:

$$
P=\frac{\text { frekuensi siswa dengan kualifikasi gaya belajar dan hasil belajar }}{\text { jumlah seluruh siswa }} \times 100 \%
$$

Data prestasi belajar didapat melalui nilai rapor siswa. Data prestasi belajar matematika siswa dikategorikan menggunakan tabel kualifikasi sebagai berikut (Arikunto, 2007) :

Tabel 1. Kualifikasi prestasi belajar

\begin{tabular}{cc}
\hline Interval presentase nilai & Kualifikasi \\
\hline $85 \leq y \leq 100$ & Amat baik \\
\hline $70 \leq y<85$ & Baik \\
\hline $55 \leq y<70$ & Cukup \\
\hline $40 \leq y<55$ & Kurang \\
\hline$y<40$ & Gagal \\
\hline
\end{tabular}

Untuk mengetahui ada atau tidaknya hubungan gaya belajar dengan prestasi belajar matematika siswa kelas XI SMK Muhammadiyah 1 Palembang digunakan persamaan regresi sederhana yang dirumuskan sebagai berikut:

$$
\mathrm{Y}^{\prime}=\mathrm{a}+\mathrm{bX}
$$

Keterangan:

$\mathrm{Y}^{\prime}$ : nilai yang diprediksi

a : konstanta atau bila nilai $\mathrm{X}=0 \quad$ (Arikunto, 2010)

b : koefisien regresi

$\mathrm{X}$ : nilai variabel independen

Untuk mencari uji hipotesis yang dilakukan adalah uji rumus korelasi Product Moment yang terdapat dalam program Statistical Product Service Solution (SPSS). Dengan menggunakan rumus sebagai berikut.

Keterangan:

$$
r_{x y}=\frac{N \sum X Y-\left(\sum X\right)\left(\sum Y\right)}{\sqrt{\left\{N \sum X^{2}--\left(\sum X^{2}\right\}\left\{N \sum Y^{2}-\left(\sum Y^{2}\right\}\right.\right.}}
$$

$r_{X Y}$ : korelasi

$X \quad$ : skor angket

$Y \quad$ : hasil tes nilai matematika

$N$ : jumlah sampel 


\section{HASIL DAN PEMBAHASAN}

Penelitian ini terdiri dari dua variabel yaitu gaya belajar siswa (variabel $\mathrm{X}$ ) dan prestasi belajar matematika (variable Y). Untuk mengetahui gaya belajar siswa (variabel X) tersebut diberikan tes angket gaya belajar kepada siswa melalui link ke google form. Prestasi belajar matematika (variabel Y) diperoleh dari data guru berupa nilai rapor matematika tahun ajaran 2020/2021.

\section{1) Gaya belajar siswa}

Skor gaya belajar siswa kelas XI SMK Muhammadiyah 1 Palembang didapat dari masing-masing gaya belajar (Visual, Audio, dan Kinestetik). Selanjutnya dilihat skor tertinggi diantara ketiga gaya belajar siswa tersebut. Berdasarkan jumlah skor tertinggi maka setiap siswa digolongkan apakah termasuk ke dalam kecenderungan gaya belajar Visual, Audio, atau Kinestetik. Berikut disajikan persentase hasil penyaringan gaya belajar siswa kelas XI SMK Muhammadiyah 1 Palembang:

Tabel 2. Gaya belajar siswa kelas XI SMK Muhammadiyah 1 Palembang

\begin{tabular}{|c|c|c|c|}
\hline Gaya belajar & Kategori & Jumlah siswa & Persentase \\
\hline Visual & Kurang & 10 & $28,57 \%$ \\
\hline Audio & Cukup & 18 & $51,43 \%$ \\
\hline Kinestetik & Sangat kurang & 7 & $20 \%$ \\
\hline \multicolumn{2}{|c|}{ Jumlah } & 35 & $100 \%$ \\
\hline
\end{tabular}

Berdasarkan hasil tes angket gaya belajar siswa dari 35 siswa, diperoleh 10 siswa $(28,57 \%)$ yang kecenderungan gaya belajarnya Visual, 18 siswa $(51.43 \%)$ kecenderungan gaya belajarnya Audio, dan 7 siswa (20\%) yang kecenderungan gaya belajarnya Kinestetik. Hal ini menunjukkan bahwa gaya belajar yang dominan dimiliki oleh siswa kelas XI SMK Muhammadiyah 1 Palembang adalah gaya belajar Audio.

\section{2) Prestasi belajar matematika}

Nilai prestasi belajar matematika siswa kelas XI SMK Muhammadiyah 1 Palembang diperoleh dari data guru berupa nilai raport matematika siswa. Berikut data kualifikasi nilai prestasi belajar matematika kelas XI menurut Tabel Kualifikasi Nilai Prestasi Belajar Matematika:

Tabel 3. Nilai prestasi belajar matematika siswa kelas XI SMK Muhammadiyah 1 Palembang

\begin{tabular}{cccc}
\hline Nilai & Kategori & Responden & Persentase \\
\hline $85 \leq y \leq 100$ & $\begin{array}{c}\text { Sangat } \\
\text { baik }\end{array}$ & 4 & $11,43 \%$ \\
\hline $70 \leq y<85$ & Baik & 29 & $82,86 \%$ \\
\hline $55 \leq y<70$ & Cukup & 2 & $5,71 \%$ \\
\hline $40 \leq y<55$ & Kurang & & \\
\hline$y<40$ & Gagal & & \\
\hline Jumlah & 35 & $100 \%$ \\
\hline
\end{tabular}


Dari perhitungan persentase tersebut dapat disimpulkan bahwa terdapat 4 siswa $(11,43 \%)$ memiliki prestasi belajar matematika berada pada kualifikasi sangat baik, terdapat 29 siswa $(82,86 \%)$ memiliki prestasi belajar matematika pada kualifikasi baik, dan terdapat 2 siswa $(5,71 \%)$ memiliki prestasi belajar matematika cukup. Dari tabel tersebut disimpulkan bahwa sebagian besar siswa kelas XI SMK Muhammadiyah 1 Palembang memiliki prestasi belajar matematika pada kualifikasi baik yaitu sebanyak 29 siswa $(82,86 \%)$.

\section{3) Hubungan gaya belajar dengan prestasi belajar matematika}

Analisis regresi yang digunakan dalam penelitian ini merupakan analisis regresi sederhana dengan satu prediktor yaitu gaya belajar (X) sebagai variabel bebas dan prestasi belajar (Y) sebagai variabel terikat. Berdasarkan analisi regresi ini dapat diketahui model regresi yang dapat digunakan untuk mengetahui bentuk hubungan antara gaya belajar dan prestasi belajar siswa. Analisis regresi dihitung menggunakan bantuan Statistical Product Service Solution (SPSS) versi 25.0 for windows.

Pada gaya belajar visual terdapat Kostanta regresi X sebesar 0,108 menyatakan bahwa setiap penambahan $1 \%$ nilai gaya belajar visual, maka nilai prestasi belajar bertambah sebesar 0,108 koefisien regresi tersebut bernilai positif. Sehingga dikatakan bahwa arah hubungan gaya belajar visual terhadap prestasi belajar adalah positif. Gaya belajar audio terdapat Kostanta regresi X sebesar 1,039 menyatakan bahwa setiap penambahan $1 \%$ nilai gaya belajar audio, maka nilai prestasi belajar bertambah sebesar 1,039 koefisien regresi tersebut bernilai positif. Sehingga dikatakan bahwa arah hubungan gaya belajar audio terhadap prestasi belajar adalah positif. Dan untuk gaya belajar kinestetik terdapat Kostanta regresi X sebesar 0,827 menyatakan bahwa setiap penambahan $1 \%$ nilai gaya belajar kinestetik, maka nilai prestasi belajar bertambah sebesar 0,827 koefisien regresi tersebut bernilai positif. Sehingga dikatakan bahwa arah hubungan gaya belajar kinestetik terhadap prestasi belajar adalah positif. Jadi maksudnya setiap gaya belajar akan mempengaruhi nilai prestasi matematika, semakin sesuai gaya belajar dengan kepribadian peserta didik, maka akan semakin tinggi pula prestasi akademik peserta didik tersebut guna mencapai prestasi belajar. Sebaliknya semakin tidak sesuai gaya belajar dengan kepribadian peserta didik, maka akan semakin rendah prestasi akademiknya, dengan begitu baik disadari maupun tidak gaya belajar merupakan kinerja dalam kegiatan belajar sehingga belajar peserta didik dapat dikatakan efektif.

Berdasarkan data di atas, menunjukkan bahwa gaya belajar yang dominan dimiliki oleh siswa kelas XI SMK Muhammadiyah 1 Palembang adalah gaya belajar Audio (pendengaran), jadi bisa dibilang bahwa siswa kelas XI SMK Muhammadiyah 1 Palembang lebih tanggap pada lingkungan luar yang lebih luas. Mereka terkadang mencari kesempatan menyimak dan mengikuti pembicaraan seseorang seperti halnya saat mereka mendengar film drama korea dan secara reflek mereka akan sangat mudah mengingat kata-kata bahasa korea tersebut. Dengan demikian menyimak dan mendengarkan merupakan kegiatan yang sering diulang-ulang oleh siswa dan menjadi sebuah kebiasaan sehingga siswa kelas XI SMK Muhammadiyah 1 Palembang dominan bergaya belajar Audio.

Setelah diadakan analisis pendahuluan kemudian dilanjutkan dengan uji hipotesis yaitu regresi linier sederhana. Pada uji ini digunakan bantuan Statistical Product Service Solution (SPSS) versi 25.0 for windows untuk menentukan seberapa besar tingkat pengaruh antar dua variabel. 
Tabel 4. Koefisien determinasi 1

\begin{tabular}{|c|c|c|c|c|}
\hline \multicolumn{5}{|c|}{ Model Summary } \\
\hline Model & $\mathrm{R}$ & R Square & $\begin{array}{l}\text { Adjusted R } \\
\text { Square }\end{array}$ & $\begin{array}{l}\text { Std. Error of the } \\
\text { Estimate }\end{array}$ \\
\hline 1 & $.605^{a}$ & .366 & .347 & 4.18091 \\
\hline
\end{tabular}

Pada tabel (model summary) menunjukkan besarnya nilai korelasi/hubungan (R) yaitu sebesar 0,605 dan koefisien determinasi (R Square) sebesar 0,366 yang mengandung pengertian bahwa keeratan variabel bebas gaya belajar terhadap variabel terikat prestasi belajar adalah sebesar 36,6\%.

Tabel 5. Anova

\begin{tabular}{|c|c|c|c|c|c|c|}
\hline \multicolumn{7}{|c|}{ ANOVA $^{a}$} \\
\hline Model & & $\begin{array}{l}\text { Sum of } \\
\text { Squares }\end{array}$ & $\mathrm{df}$ & $\begin{array}{c}\text { Mean } \\
\text { Square }\end{array}$ & $\mathrm{F}$ & Sig. \\
\hline \multirow[t]{3}{*}{1} & Regression & 332.761 & 1 & 332.761 & 19.037 & $.000^{\mathrm{b}}$ \\
\hline & Residual & 576.839 & 33 & 17.480 & & \\
\hline & Total & 909.600 & 34 & & & \\
\hline
\end{tabular}

a. Dependent Variable: PRESTASI BELAJAR

b. Predictors: (Constant), GAYA BELAJAR

Bagian tabel ini menunjukkan besarnya angka probabilitas atau signifikan pada perhitungan ANOVA yang digunakan untuk uji kelayakan model regresi dengan ketentuan angka probabilitas/signifikan/sig yang baik untuk digunakan sebagai model regresi yaitu harus $>0,05$. Dari output tersebut nilai $F_{\text {hitung }}=19,073$ dengan tingkat signifikan $<$ probabilitas $(0,000<0,005)$ maka model regresi dapat digunakan untuk memprediksi variabel prestasi belajar matematika. Untuk menguji apakah benar variabel bebas gaya belajar mempengaruhi variabel terikat prestasi belajar matematika siswa, dapat dilakukan pengujian dengan menggunakan angka $\mathrm{F}$ dari keluaran ANOVA di atas.

Tabel 6. Koefisien regresi

\begin{tabular}{|c|c|c|c|c|c|c|}
\hline & & Coef & icients $^{a}$ & & & \\
\hline & & $\begin{array}{l}\text { Unstan } \\
\text { Coeff }\end{array}$ & $\begin{array}{l}\text { ardized } \\
\text { cients }\end{array}$ & $\begin{array}{c}\text { Standardiz } \\
\text { ed } \\
\text { Coefficient } \\
\text { s }\end{array}$ & & \\
\hline & & B & Std. Error & Beta & $\mathrm{t}$ & Sig. \\
\hline 1 & (Constant) & 21.091 & 12.879 & & 1.638 & .111 \\
\hline & $\begin{array}{l}\text { GAYA BELAJAR } \\
\text { KINESTETIK }\end{array}$ & .980 & .225 & .605 & 4.363 & .000 \\
\hline
\end{tabular}

Berdasarkan nilai signifikan dari tabel coefficients diperoleh nilai signifikan sebesar $0,000<0,05$, sehingga dapat disimpulkan bahwa variabel gaya belajar $(\mathrm{X})$ berhubungan terhadap variabel prestasi belajar (Y). 
Tabel 7. Korelasi

\begin{tabular}{|c|c|c|c|}
\hline \multicolumn{4}{|c|}{ Correlations } \\
\hline & & $\begin{array}{c}\text { Gaya belajar } \\
\text { siswa }\end{array}$ & Prestasi belajar \\
\hline \multirow[t]{3}{*}{ Gaya belajar siswa } & Pearson Correlation & 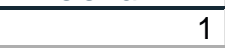 & $.605^{\star \star}$ \\
\hline & Sig. (2-tailed) & & .000 \\
\hline & $\mathrm{N}$ & 35 & 35 \\
\hline \multirow[t]{3}{*}{ Prestasi belajar } & Pearson Correlation & $.605^{\star \star}$ & 1 \\
\hline & Sig. (2-tailed) & .000 & \\
\hline & $\mathrm{N}$ & 35 & 47 \\
\hline
\end{tabular}

Dari hasil perhitungan pada tabel di atas dapat diketahui nilai hubungan antara variabel X (gaya belajar) dengan variabel Y (prestasi belajar matematika) adalah 0,605 . Nilai tersebut signifikan pada alpha 0,01 dan dikuatkan dengan tanda (**) yang menjelaskan kedua variabel tersebut sangat korelatif. Hasil tersebut menunjukkan bahwa nilai $r_{\text {hitung yang lebih besar }} r_{\text {tabel }}(0,605>2,035)$, oleh karena itu dapat disimpulkan bahwa terdapat hubungan yang positif antar kedua variabel. Dengan demikian dari penelitian di atas menunjukkan bahwa hipotesis kerja (Ha) yang berbunyi: "ada hubungan gaya belajar terhadap prestasi belajar matematika siswa kelas XI SMK Muhammadiyah 1 Palembang" diterima. Dengan kata lain semakin tinggi gaya belajar siswa maka semakin baik pula prestasi belajar matematika siswa.

Dapat disimpulkan juga bahwa semakin besar nilai gaya belajar siswa maka semakin besar pula nilai prestasi belajarnya, begitupun sebaliknya semakin kecil nilai gaya belajar siswa maka semakin kecil pula nilai prestasi belajar siswa. Dengan demikian dari penelitian ini menunjukkan bahwa ada hubungan gaya belajar terhadap prestasi belajar matematika siswa kelas XI SMK Muhammadiyah 1 Palembang. Karena kenyataannya gaya belajar memiliki hubungan yang positif dan signifikan dengan prestasi belajar, keeratan hubungan gaya belajar terhadap prestasi belajar sebesar $36,6 \%$.

Perlu ditekankan di sini, yang dimaksud semakin besar nilai gaya belajar siswa maka semakin besar pula nilai prestasi belajarnya, begitupun sebaliknya semakin kecil nilai gaya belajar siswa maka semakin kecil pula nilai prestasi belajar siswa, yaitu jika siswa menerima pembelajaran sesuai dengan gaya belajarnya maka akan mempermudah siswa tersebut menerima bahan pembelajarannya.

Penelitian ini sejalan dengan hasil penelitian Pujiarti (2013) mengenai hubungan antara gaya belajar dengan prestasi belajar pada siswa kelas V SD Negeri Percobaan 4 Wates Kulon Progo Tahun Ajaran 2012/2013 dengan kesimpulan sebagai berikut: (1) Ada hubungan positif dan signifikan antara gaya belajar dengan prestasi belajar siswa kelas V SD Negeri Percobaan 4 Wates Kulon Progo Tahun Ajaran 2012/2013; (2) Keeratan hubungan antara gaya belajar dengan prestasi belajar siswa kelas V SD Negeri Percobaan 4 Wates Kulon Progo Tahun Ajaran 2012/2013 sebesar $22,1 \%$.

Penelitian Bire, Geradus, dan Bire (2014) juga menyatakan bahwa (1) terdapat pengaruh yang signifikan gaya belajar visual, auditorial, dan kinestetik terhadap prestasi belajar; (2) hasil uji determinasi menunjukkan sumbangan relatif gaya belajar visual, auditorial, dan kinestetik terhadap prestasi belajar siswa sebesar $34,8 \%$. Sumbangan relatif masing-masing terhadap prestasi belajar, yakni: gaya 
belajar visual 26,4\%, gaya belajar auditorial $24,2 \%$, dan gaya belajar kinestetik $26,2 \%$

\section{SIMPULAN DAN SARAN}

Berdasarkan hasil penelitian dan pembahasan, dapat disimpulkan bahwa ada hubungan gaya belajar dengan prestasi belajar siswa kelas XI SMK Muhammadiyah 1 Palembang.

Disarankan pada guru agar lebih memperhatikan gaya belajar siswa pada setiap mata pelajaran terutama mata pelajaran matematika, karena dengan mengetahui gaya belajar siswa, maka akan mempermudah siswa dalam menerima dan memahami materi pelajaran dan dengan demikian siswa mampu mencapai prestasi belajarnya dengan baik.

\section{DAFTAR PUSTAKA}

Arikunto, S. 2007. Dasar-dasar Evaluasi Pendidikan. Jakarta: PT. Bumi Aksara. Arikunto, S. 2010. Prosedur Penelitian. Jakarta: Rineka Cipta.

Bire, A. L., Geradus, U., dan Bire, J. 2014. Pengaruh Gaya Belajar Visual, Auditorial, dan Kinestetik Terhadap Prestasi Belajar Siswa. Jurnal Kependidikan: Penelitian Inovasi Pembelajaran, Vol. 44(2) : 168-174.

Budiarti, I. dan Jabar, A. 2016. Pengaruh Gaya Belajar Terhadap Hasil belajar Matematika siswa Kelas VIII SMPN 2 Banjarmasin Tahun Ajaran 2015/2016. Math Didactic: Jurnal Pendidikan Matematika, Vol. 2(3) : 142-147.

DePorter, B. dan Hernacki, M. 2014. Quantum Learning Membiasakan Belajar Nyaman dan Menyenangkan. Bandung: Kaifa.

Peraturan Menteri Pendidikan Nasional Republik Indonesia nomor 22 tahun 2006. [Online]. https://akhmadsudrajat.files.wordpress.com/2009/04/permendiknas-no-22tahun-2006.pdf

Pujiarti, A. 2013. Hubungan Antara Gaya Belajar dengan Prestasi Belajar Siswa Kelas V SD Negeri Percobaan 4 Wates Kulon Progo Tahun Ajaran 2012/2013. Skripsi tidak diterbitkan. Yogyakarta: Universitas Negeri Yogyakarta. [Online].

Tersedia: https://eprints.uny.ac.id/15771/1/SKRIPSI\%20AMIN\%2009108241017\%20P DF.pdf

Sugiyono. 2011. Metode Penelitian Pendidikan. Bandung: Alfabeta.

Tualeka, F. 2020. Pengaruh Gaya Belajar Siswa Terhadap Hasil Belajar Matematika Pada Materi SPLDV Kelas VIII SMP Negeri 23 Ambon. Skripsi tidak diterbitkan. Ambon: Institut Agama Islam Negeri Ambon. [Online]. Tersedia: http://repository.iainambon.ac.id/807/1/BAB\%201\%2C3\%2C5.pdf

Wardhani, I.S., Hanik, U., dan Wulandari, R. 2016. Pengaruh Gaya Belajar Terhadap Hasil Belajar Matematika Mahasiswa Universitas Trunojoyo. JP2M (Jurnal Pendidikan dan Pembelajaran Matematika), Vol. 2(1) : 42-54. 